\title{
Tolerance and dose-volume relationship of intrathoracic stomach irradiation after esophagectomy for patients with thoracic esophageal squamous cell carcinoma
}

\author{
Qi Liu ${ }^{1,2, *}$, Xu-Wei Cai ${ }^{1,2,3, *}$, Xiao-Long Fu ${ }^{1,2,3}$, Jun-Chao Chen ${ }^{1,2}$, Jia-Qing Xiang ${ }^{2,4}$ \\ ${ }^{1}$ Department of Radiation Oncology, Fudan University Shanghai Cancer Center, Shanghai, China \\ ${ }^{2}$ Department of Oncology, Shanghai Medical College, Fudan University, Shanghai, China \\ ${ }^{3}$ Department of Radiation Oncology, Shanghai Jiaotong University Chest Hospital, Shanghai, China \\ ${ }^{4}$ Department of Thoracic Surgery, Fudan University Shanghai Cancer Center, Shanghai, China \\ *These authors have contributed equally to this work \\ Correspondence to: \\ Xiao-Long Fu, e-mail: xlfu1964@hotmail.com \\ Keywords: Clinical Section, esophageal carcinoma, radiotherapy, toxicity, intrathoracic stomach \\ Received: May 08, $2015 \quad$ Accepted: July 24, $2015 \quad$ Published: August 05, 2015
}

\section{ABSTRACT}

Purpose: To identify the tolerance of radiation with a high prescribed dose and predictors for the development of intrathoracic stomach toxicity in patients with thoracic esophageal squamous cell carcinoma (SCC) after esophagectomy followed by gastric conduit reconstruction.

Methods and Materials: From 2011 to 2013, 105 patients after esophagectomy were treated with postoperative radiotherapy. The intrathoracic stomach was outlined with the calculation of a dose-volume histogram (DVH) for the initial intended treatment of $6020 \mathrm{cGy}$ or $6300 \mathrm{cGy}$. The volume of the intrathoracic stomach receiving each dose was recorded at 10-Gy intervals between 10 and $40 \mathrm{~Gy}$ and at 5-Gy intervals between 40 and $60 \mathrm{~Gy}$. The grade of toxicities was defined by the National Cancer Institute Common Toxicity Criteria version 4.0.

Results: The mean and maximum doses of the intrathoracic stomach were 2449 \pm 986 cGy and $6519 \pm 406$ cGy, respectively. Sixteen $(15.2 \%)$ and three $(2.9 \%)$ experienced Common Toxicity Criteria Grade 2 and Grade 3 acute gastric toxicity. There were no Grade 4 toxicities. Fourteen patients (13.3\%) exhibited late gastric complications possibly related to radiation. The volume percent of the intrathoracic stomach receiving at least $50 \mathrm{~Gy}\left(\mathrm{~V}_{50}\right)$ was strongly associated with the degree of toxicity $(p=0.024$, respectively). Multivariate analysis of patient and treatmentrelated factors revealed no other significant predictors of severe toxicities.

Conclusion: The intrathoracic stomach is well tolerated with a high-dose irradiation for patients with esophageal SCC receiving radiotherapy after esophagectomy. A strong dose-volume relationship exists for the development of Grade 2 acute intrathoracic stomach toxicity in our study.

\section{INTRODUCTION}

Existing evidences have indicated that overall survival (OS) could be improved using neoadjuvant chemoradiotherapy followed by surgery for esophageal cancer [1]. However, neoadjuvant therapy might increase the risk of postoperative morbidity or perioperative mortality [2], so a considerable number of patients with local advanced thoracic esophageal squamous cell carcinoma (SCC) in our country perform surgery as their initial treatment. However, sometimes it is difficult to achieve the purpose of complete resection because of surgeons' skills. Moreover, according to previous studies the recurrence rate of SCC is as high as $40 \%-50 \%$ after radical surgery, and locoregional recurrence accounts for more than half of treatment failures [3-4], even among patients with a pathologically complete response to neoadjuvant chemoradiotherapy [5]. Recurrences in 
supraclavicular and superior mediastinal areas were the most common failures [6-7]. It further necessitates the need for adjuvant therapy to decrease the likehood of local recurrence, especially for patients with positive lymph nodes [8-9]. Radiotherapy(RT) is also a crucial treatment for locoregional failures. Usually, the radiation dose is - as high as possible for patients with limited lesions.

Stomach is the first choice for esophageal replacement following esophagectomy. Recently, gastric tube has gained wide acceptance for esophageal reconstruction, which significantly improve the quality of postoperative life. In our center most of patients received esophagectomy with gastric tube reconstruction and intrathoracic anastomosis via the retrosternal route. As a result, the intrathoracic stomach is often incidentally irradiated in postoperative thoracic radiotherapy. Therefore, when formulating radiation plans for patients who have undergone surgery, the intrathoracic stomach need to be protected to avoid severe complications such as marginal ulcers, bleeding, perforation and anastomotic fistula, as RT-induced injury could occur hours to weeks after the first treatment [10]. Gastroduodenal (GD) tolerance to RT has been investigated in abdominal malignancies [11-12], but the application of these results to esophageal SCC patients requires caution. The reason is there are very few published reports of acute and late RT effects on the intrathoracic stomach, and whether the effects would influence the functions of the gastric substitute is not well known.

Due to technical limitations of 2-dimensional RT, the actual dose distribution of organs at risk could not be analyzed. Currently, developed three-dimensional conformal RT (3D-CRT) has been succeed in providing the possibility of analyzing dose-toxicity relationship and decreasing certain toxicities in esophageal SCC patients.
In the present study, various clinical and dose-volume histogram (DVH) parameters were analyzed based on a widely used radiation system in order to identify a potentially safe dose tolerance of the intrathoracic stomach and risk factors for gastric toxicity by observing the radiation-induced adverse side effects in a group of patients from a randomized phase II clinical trial (http:// ClinicalTrials.gov website, number NCT01391572) who received thoracic RT after esophagectomy.

\section{MATERIALS AND METHODS}

\section{Patient population and treatment}

Between May 2011 and December 2013, patients from 6 centers with esophageal SCC undergoing surgical resection followed by gastric tube reconstruction enrolled our clinical trial. The patients were included if their pathological stage was $\mathrm{T}_{3-4} \mathrm{~N}_{0-3} \mathrm{M}_{0}$ according to the AJCC/UICC TNM staging system (Version 7.0, 2009) and if they did not receive neoadjuvant therapy. Patients without postoperative RT or available DVH data were ineligible (Figure 1).

All patients underwent esophagectomy through right thorax and abdominal incisions and done in esophageal reconstruction. The intrathoracic stomach was formed from the distal aspect of the lesser curvature of the stomach with application of linear staplers. It was created by resection of the lesser curvature and formation of the gastric conduit (4-6 cm in diameter). And then, the tubular stomach was pulled upward to the cervical or aortic arch part through the posterior mediastinal route and performed two-layer anastomosis. All included patients were never diagnosed with gastric ulcers, reflux esophagitis and other serious gastrointestinal diseases that would preclude safe administration of treatment.

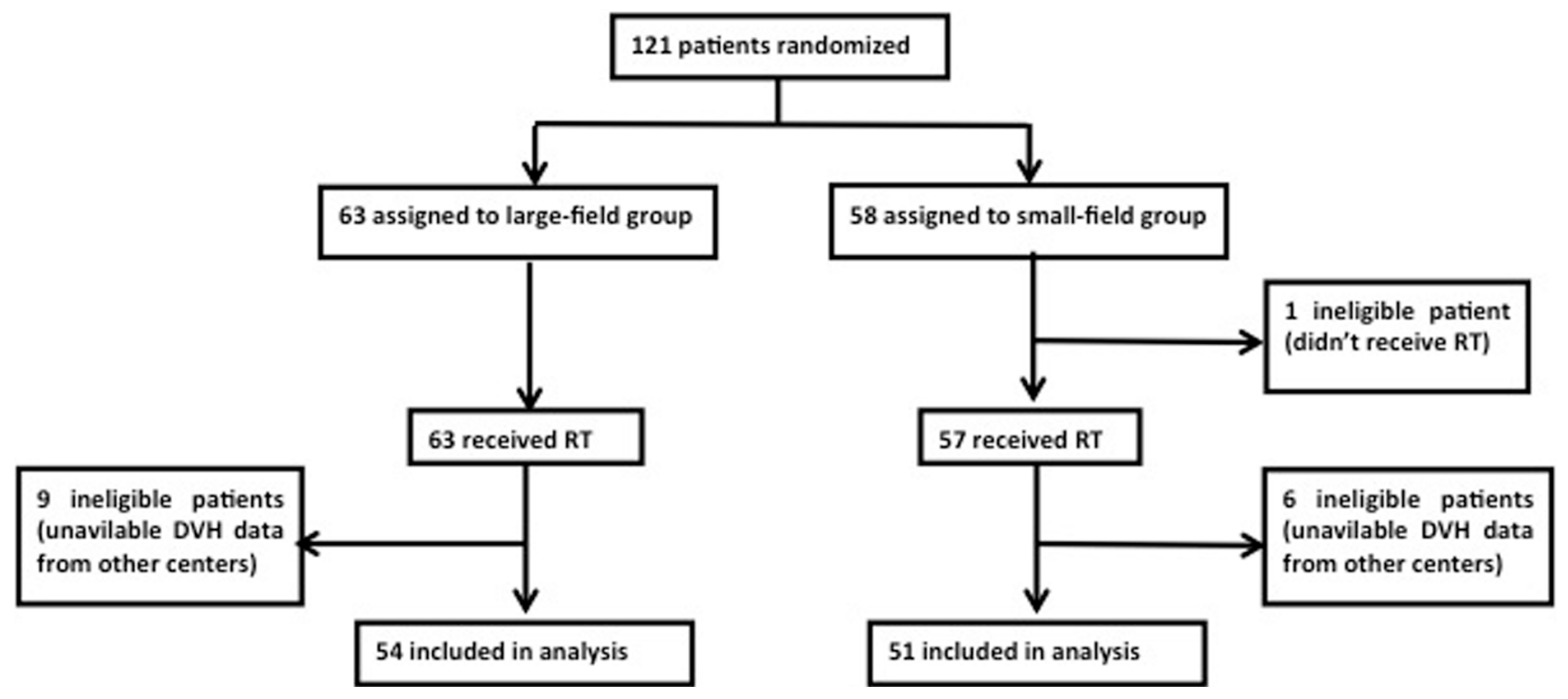

Figure 1: CONSORT diagram for the study. RT = radiotherapy. 
Components of the pre-radiation process included the following: a complete history and physical examination; complete blood cell counts; serum biochemical assays; barium esophagram to exclude evidence of gastric perforation, anastomotic fistula, or deep ulceration to the mediastinum; chest CT scans; and ultrasonographic examination to rule out distant metastases in the neck, liver, kidney, spleen, and retroperitoneal lymph nodes.

All patients underwent CT-based treatment simulation while supine, and 5-mm-thick images were obtained throughout the entire neck, thorax, and upper abdomen. The clinical tumor volumes (CTVs) encompassed the tumor bed and/or the bilateral supraclavicular and upper mediastinal lymphatic drainage areas. Planning target volumes (PTVs) were defined as the CTV plus a uniform 1-cm margin. According to the protocol for estimating the optimal radiation volume of postoperative radiation, all patients were assigned into either the large-field group (including tumor bed, bilateral supraclavicular and upper mediastinal lymphatic drainage areas) or the small-field group (only the tumor bed area) by random number table. A simultaneous integrated-boost intensity-modulated radiotherapy (SIBIMRT) technique was used, and treatment plans were generated by the Pinnacle treatment planning system (Philips Medical Systems). Radiation was delivered with 6-MV photons by a linear accelerator. The prescribed doses of the tumor bed area were 60.2 Gy (in 28 fractions of $2.15 \mathrm{~Gy} /$ fraction) using a 6-MV X-ray for patients with T3-stage disease or 63 Gy (in 28 fractions of 2.25 Gy/fraction) for patients with T4-stage disease. The lymphatic drainage area in the large-field group was prescribed a dose of 50.4 Gy (Figure 2). The goals were to deliver the prescription dose to at least $95 \%$ of the PTV and $95 \%$ of the prescribed dose to at least $99 \%$ of the PTV. The normal tissue constraints met the following criteria: (1) maximum spinal cord dose $\leq 45 \mathrm{~Gy}$; (2) lung $\mathrm{V} 20 \leq 25 \%$ and mean lung dose (MLD) $\leq 15 \mathrm{~Gy}$; and (3) mean heart dose $\leq 30 \mathrm{~Gy}$. The intrathoracic stomach was not designated as a constrained structure for the original treatment plans. All patients were required to fast during simulation and irradiation.

\section{Follow-up and diagnosis of gastric toxicity}

Follow-up occurred 4-6 weeks after treatment completion and every 3 months thereafter. Complete history and physical examinations, including an evaluation of digestive symptoms, were performed at each visit. Re-examinations included endoscopy, cervical ultrasounds, chest-enhanced CT scans, abdominal ultrasound screening, and, when necessary, bone emission computed tomography (ECT) and positron emission tomography $(\mathrm{PET}) / \mathrm{CT}$. Gastric toxicity was defined as the new development of or the aggravation of endoscopic abnormalities, such as erosive gastritis or a gastric ulcer in close proximity to the RT field following RT. Assessment of digestive symptoms was adapted from the Common Toxicity Criteria for Adverse Events, version 4.0.
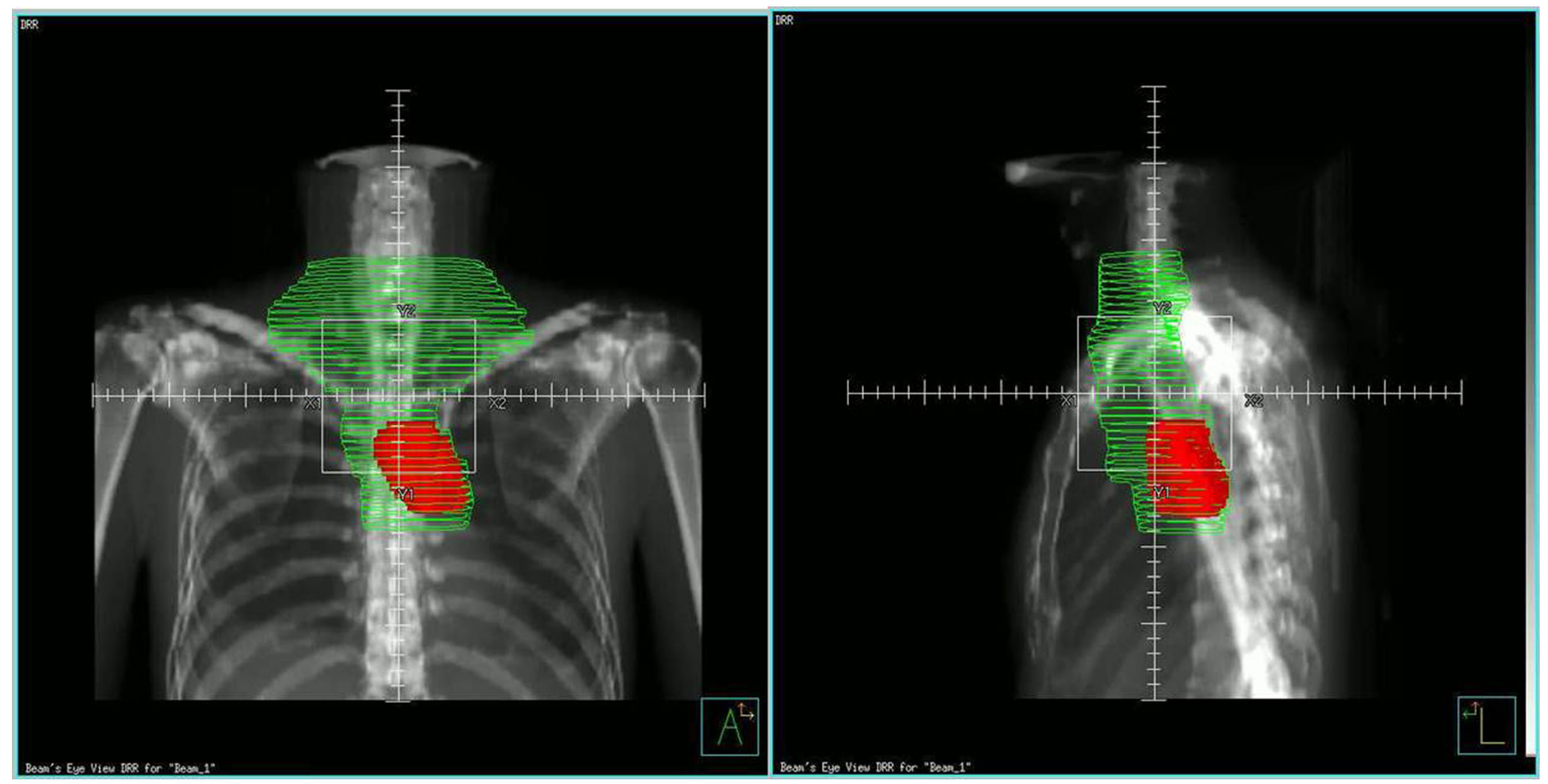

Figure 2: The radiation plan displays on the coronal and sagittal planes. Red shading indicates the planning tumor volume (PTV) of small field group (tumor bed area only), the green line outlines the PTV of large-field group including bilateral supraclavicular and upper mediastinal lymphatic drainage area and tumor bed area. 


\section{Dosimetric evaluation of the intrathoracic stomach}

Intrathoracic stomach contour $\left(\mathrm{PTV}_{\text {sto }}\right)$ was defined as a three-dimensional expansion of the intrathoracic tubular stomach. DVH were recorded for the lung, heart, spinal cord, intrathoracic stomach and PTV in all patients. The dosimetric parameters from DVHs were as follows: (1) $\mathrm{D}_{\max }$ : maximum dose, (2) $\mathrm{D}_{\text {mean }}$ : mean dose (3) $\mathrm{V}_{\text {dose }}$ : percentage volume receiving more than the irradiated dose and (4) $\mathrm{aV}_{\text {dose }}$ : absolute volume receiving more than the irradiated dose. The range of the intrathoracic stomach volume in $10 \mathrm{~Gy}\left(\mathrm{~V}_{10}\right)$ to $40 \mathrm{~Gy}\left(\mathrm{~V}_{40}\right)$, at $10 \mathrm{~Gy}$ intervals and in $40 \mathrm{~Gy}\left(\mathrm{~V}_{40}\right)$ to $60 \mathrm{~Gy}\left(\mathrm{~V}_{60}\right)$, at 5 Gy intervals was acquired. Patients with Grade 2 toxicity and above were analyzed further to determine their risk of developing toxicity according to the dose-volume parameters.

\section{Statistical analysis}

The primary endpoint was the occurrence and severity of toxicity. Continuous variables were summarized by descriptive statistics, and categorical variables were tabulated as frequencies and percentages. Dosimetric comparisons between small-field and large-field group were performed with independent sample $t$-tests in all patients. The association between toxicity grade $(0-1$ vs. $\geq 2)$ and irradiated stomach volume and other clinical and treatment-associated factors were analyzed by multiple logistic regression. Factors analyzed included the following: age, gender, irradiation volume, anastomotic location, surgery procedure and location of the intrathoracic stomach. The area under the curve (AUC) was calculated to determine the cut-off value of the best predictors. Statistical analyses were performed with Statistical Package for the Social Sciences software (Version 13.0, Chicago, IL, USA). All tests were twosided, and $P$-values less than 0.05 were considered significant.

\section{RESULTS}

A total of 105 patients with esophageal SCC were identified for analysis. Table 1 lists the patient and tumor characteristics. The median age of patients included in the study was 58 years (range, 40-71). The median followup time was 16.0 months (range, 3.0-37.3 months). The cases included 79 (75.2\%) cervical anastomoses and 26 $(24.8 \%)$ aortic anastomoses. The median volume of the intrathoracic stomach was $229.06 \mathrm{ml}(73.24-440.50 \mathrm{ml})$, the $\mathrm{D}_{\max }$ of $\mathrm{PTV}_{\text {sto }}$ was $6519 \pm 406 \mathrm{cGy}$, and the $\mathrm{D}_{\text {mean }}$ was $2449 \pm 986 \mathrm{cGy}$. Among the 51 patients in the small-field group, the $\mathrm{D}_{\text {mean }}$ and $\mathrm{D}_{\text {max }}$ of $\mathrm{PTV}_{\text {sto }}$ were $2062 \mathrm{cGy}$ and $6374 \mathrm{cGy}$, respectively, compared with $2813 \mathrm{cGy}$ and 6657 cGy, respectively among the 54 patients in the large-field group (both $p<0.001$, respectively). Independent sample $t$-tests found all mean $\mathrm{aV}_{\text {dose }}$ and $\mathrm{V}_{\text {dose }}$ parameters but $\mathrm{aV}_{60}$ and $\mathrm{V}_{60}$ significantly higher in the large-field group than the small-field group ( $p<0.05$, showed in Table 2$)$.

Treatment toxicities were classified according to the clinical symptoms. Overall, the maximum acute gastric toxicities encountered during RT were Grade 0 in 82 patients (78.1\%), Grade 1 in 4 patients (3.8\%), Grade 2 in 16 patients $(15.2 \%)$ and Grade 3 in 3 patients $(2.9 \%)$. There were no Grade 4 toxicities and no treatment-related deaths. None of patients required a treatment break because of gastric toxicity. The cases exhibited Grade 2 and above acute digestive reactions, including 2 with abdominal pain (1.9\%), 9 with anorexia (8.6\%), 8 with sour regurgitation (7.6\%), and 4 with gastrectasia (3.8\%). All 3 cases with Grade 3 toxicity was anorexia. The median time to the onset of these symptoms was 16 days (range, 1-40 days).

During the follow-up period, 15 (14.3\%) patients suffered from grade 2 and above late toxicities, including $7(6.7 \%)$ with severe anastomotic obstruction, 4 (3.8\%) with severe gastritis, $2(1.9 \%)$ with remnant gastric ulcer, $1(1.0 \%)$ with gastric bleeding and $1(1.0 \%)$ with bronchial stump gastric fistula. The patients who suffered from gastric bleeding and bronchial stump gastric fistula died from their complications. The median time to the onset of late toxicities was 4.5 months (range, 1.0-12.0 months). Moreover, the incidences of acute $(35.2 \%$ vs. $29.4 \%$, $p=0.527)$ and late gastric toxicities (18.5\% vs. $9.8 \%$, $p=0.202)$ in the large-field group were a little higher than those in the small-field group, but no statistically significant difference was found.

By multiple logistic regression analysis, $\mathrm{V}_{50}$ was the only predictive factor for Grade 2 and above gastric toxicity $(p=0.024$, Table 3$)$. ROC curve analysis showed that the cut-off value of $\mathrm{V}_{50}$ was $14.05 \%(0.815,95 \%$ CI:0.685-0.946; the sensitivity and specificity were $82.4 \%$, and $61.3 \%$, respectively) and that the rates of Grade 2 and above acute and late toxicities were $19.1 \%$ for $\mathrm{V} 50<14.05 \%$ and $34.5 \%$ for $\mathrm{V} 50>14.05 \%$.

\section{DISCUSSION}

Our results show that $\geq$ grade 2 acute and late gastric toxicity occurred in $18.1 \%$ and $14.3 \%$ of patients, respectively, and that an RT dose-volume effect for stomach toxicity was shown. $\mathrm{V}_{50}$ was the most predictive factor for $\geq$ grade 2 toxicity for the stomach.

In the era of 3D-CRT, upper digestive tract tolerance to RT has been investigated in abdominal malignancies. The overall incidence of GD toxicity after RT was reported to be between $5.7 \%$ and $23.1 \%$ in hepatocellular carcinoma [13-15]. The risk of grade 2 and greater GD toxicities was reported to be between $33 \%$ and $80 \%$ when combined with chemotherapy in pancreatic cancer [11-12, 16]. In two retrospective studies for esophageal cancer, the risk of acute toxicity in the upper aerodigestive tract 
Table 1: Patients characteristics.

\begin{tabular}{|l|l|c|c|c|c|}
\hline \multicolumn{2}{l}{ Large-field } & \multicolumn{2}{c}{ Small-field } & \multicolumn{2}{c}{ Total } \\
\hline & Male & 46 & 45 & 91 & 0.646 \\
\hline & Female & 8 & 6 & 14 & \\
\hline Length & $<=4 \mathrm{~cm}$ & 33 & 34 & 67 & 0.694 \\
\hline & $>4 \mathrm{~cm}$ & 21 & 17 & 38 & \\
\hline Pathological & well & 2 & 3 & 5 & 0.823 \\
\hline differentiation & Moderately & 33 & 28 & 61 & \\
\hline & poorly & 18 & 15 & 33 & \\
\hline Tumor location & Upper thoracic & 3 & 4 & 7 & 0.611 \\
\hline & Middle thoracic & 24 & 18 & 42 & \\
\hline & Lower thoracic & 27 & 29 & 56 & \\
\hline T stage & T3 & 52 & 44 & 96 & 0.067 \\
\hline & T4 & 2 & 7 & 9 & \\
\hline N stage & N0 & 25 & 20 & 45 & 0.174 \\
\hline & N1-3 & 29 & 31 & 60 & \\
\hline Stomach location & Postmediastinum & 25 & 15 & 40 & 0.195 \\
\hline & Left thoracic cavity & 4 & 6 & 10 & \\
\hline & Right thoracic cavity & 25 & 30 & 55 & \\
\hline Anastomosis & Cervix & 39 & 40 & 79 & 0.461 \\
\hline & Intrathoracic & 15 & 11 & 26 & \\
\hline Lymphadenectomy & Two-field & 49 & 45 & 94 & 0.675 \\
\hline & Three-field & 5 & 6 & 11 & \\
\hline & & & & & \\
\hline
\end{tabular}

and stomach was $2.3 \%-11.9 \%$ for the small $\mathrm{T}$ portal group and $12 \%-18.6 \%$ for the large $\mathrm{T}$ portal group [ 8 , 17], which was similar to our results. Cosset et al. [18] reported severe late gastric complications included ulcers $(n=25)$ and severe gastritis $(n=2)$ among 516 patients with Hodgkin's disease treated by RT close to $40 \mathrm{~Gy}$. Chen et al. also reported the risk of late complications in their study, 1 of 355 patients experienced grade 2-3 gastric bleeding and another 4 patients experienced grade 5 gastric bleeding after postoperative radiation. In a phase II trial of postoperative concurrent chemoradiotherapy, $8 \%$ patients experienced grade 3-4 upper digestive tract toxicity, and $6 \%$ patients required an unplanned hospitalization [19]. The use of concurrent chemotherapy, differences in RT volume and prescribed dose, and selection bias for the study population may explain the different rates of modest complications in these studies. The irradiated dose in our study was higher when being converted into the biologically effective dose (BED), while partial patients' irradiated volumes were smaller than in previous studies.

In early reports, the gastric ulceration and perforation rates were $4 \%$ and $2 \%$ vs. $16 \%$ and $14 \%$ after doses $<50$ Gy vs. $\geq 50$ Gy [10]. Emami et al. [20] demonstrated the tolerance dose for late gastric ulceration was 50,55 , and 60 Gy for the whole stomach, $2 / 3$ of the stomach, and 1/3 of the stomach, as a suggestion for TD5/5 (the probability of $5 \%$ complication within 5 years). However, they did not offer estimates to predict acute toxicities. Currently, for stomach tolerance, the current Quantitative Analysis of Normal Tissue Effects in the Clinic (QUANTEC) report recommends dose constraints of the stomach for patients with abdominal tumors as follows: whole stomach $50 \mathrm{~Gy}$ (range of maximum 45-54 Gy) and partial volume dose limits of $2 \% \mathrm{~V}_{50}-10 \% \mathrm{~V}_{45}$. [21]. However, these data may not be applicable for esophageal SCC patients because (1) anatomical structures change after surgery, generally causing some scar tissue in the thoracic and peritoneal cavity; (2) intrathoracic stomach tube for upper digestive tract reconstruction contributes to the development of digestive diseases; and (3) the prescribed dose of thoracic radiation always exceeds $50 \mathrm{~Gy}$, even more than $60 \mathrm{~Gy}$. A dose of 50 Gy has endured as a broad dose limit guideline when irradiated fields encompass a large portion of the stomach, albeit with rather limited support from actual published data [10]. However, nearly all of the patients in our study received intrathoracic stomach irradiation 
Table 2: Comparison between small-field group and large-field group in dosimetric parameters

\begin{tabular}{|c|c|c|c|}
\hline & Small-field group & Large-field group & $P$ \\
\hline $\mathrm{aV} 10(\mathrm{ml})$ & 118.48 & 149.84 & 0.019 \\
\hline $\mathrm{aV} 20(\mathrm{ml})$ & 92.96 & 125.01 & 0.005 \\
\hline $\mathrm{aV} 30(\mathrm{ml})$ & 72.78 & 104.23 & 0.001 \\
\hline $\mathrm{aV} 40(\mathrm{ml})$ & 49.62 & 79.99 & 0.001 \\
\hline $\mathrm{aV} 45(\mathrm{ml})$ & 41.07 & 68.14 & 0.001 \\
\hline $\mathrm{aV} 50(\mathrm{ml})$ & 33.88 & 56.80 & 0.001 \\
\hline $\mathrm{aV} 55(\mathrm{ml})$ & 27.15 & 38.04 & 0.03 \\
\hline $\mathrm{aV60}(\mathrm{ml})$ & 22.20 & 25.03 & 0.521 \\
\hline V10(\%) & 50.1 & 63.3 & 0.001 \\
\hline V20(\%) & 39.6 & 54.2 & 0.001 \\
\hline V30(\%) & 31.9 & 46.6 & 0.001 \\
\hline V40(\%) & 22.4 & 37.7 & 0.001 \\
\hline V45(\%) & 18.8 & 33.2 & 0.001 \\
\hline V50(\%) & 15.4 & 28.6 & 0.001 \\
\hline V55(\%) & 12.7 & 19.8 & 0.012 \\
\hline V60(\%) & 10.6 & 13.5 & 0.248 \\
\hline
\end{tabular}

Table 3: Multiple analyses of the risk factors related to Grade 2 and above gastric toxicities

\begin{tabular}{|c|c|c|c|c|}
\hline \multirow[t]{2}{*}{ Variables } & & \multicolumn{3}{|c|}{ Multiple regression } \\
\hline & & $\operatorname{Exp}(B)$ & $95 \%$ CI & $P$ value \\
\hline Age & & 1.090 & $0.999-1.189$ & 0.054 \\
\hline Gender & Male vs. Female & 1.774 & $0.300-10.500$ & 0.527 \\
\hline Irradiation volume & Large field vs. Small field & 3.777 & $0.656-21.751$ & 0.137 \\
\hline Anastomotic location & Cervix vs. Intrathoracic & 2.683 & $0.592-12.147$ & 0.200 \\
\hline Surgery procedure & Two-field vs. Three-field & 1.096 & $0.199-6.044$ & 0.916 \\
\hline $\begin{array}{l}\text { Location of intrathoracic } \\
\text { stomach }\end{array}$ & Postmediastinum vs. Thoracic cavity & 3.536 & $0.382-32.76$ & 0.266 \\
\hline T stage & T3 vs.T4 & 0.541 & $0.043-6.833$ & 0.635 \\
\hline V10 & & 0.025 & $0.001-9.890$ & 0.483 \\
\hline V20 & & 2.43 & $0.000-9.172$ & 0.446 \\
\hline V30 & & 2.615 & $0.000-5.648$ & 0.704 \\
\hline V40 & & 1.300 & $0.286-3.331$ & 0.883 \\
\hline V45 & & 6.356 & $0.358-65.261$ & 0.958 \\
\hline V50 & & 13.815 & $1.42-134.38$ & 0.024 \\
\hline V55 & & 13.988 & $0.783-249.78$ & 0.073 \\
\hline V60 & & 7.989 & $0.304-209.782$ & 0.213 \\
\hline
\end{tabular}

(Continued) 


\begin{tabular}{|c|c|c|c|}
\hline \multirow[t]{2}{*}{ Variables } & \multicolumn{3}{|c|}{ Multiple regression } \\
\hline & $\operatorname{Exp}(B)$ & $95 \% \mathrm{CI}$ & $P$ value \\
\hline $\mathrm{aV} 10$ & 1.01 & $0.900-1.134$ & 0.206 \\
\hline aV20 & 0.913 & $0.706-1.181$ & 0.252 \\
\hline $\mathrm{aV} 30$ & 1.232 & $0.901-1.686$ & 0.183 \\
\hline $\mathrm{aV} 40$ & 0.521 & $0.306-1.127$ & 0.171 \\
\hline $\mathrm{aV} 45$ & 0.573 & $0.323-1.144$ & 0.224 \\
\hline aV50 & 0.646 & $0.358-1.163$ & 0.274 \\
\hline aV55 & 0.855 & $0.485-1.506$ & 0.082 \\
\hline aV60 & 0.984 & $0.645-1.502$ & 0.060 \\
\hline $\mathrm{D}_{\max }$ & 1.000 & $0.999-1.002$ & 0.688 \\
\hline $\mathrm{D}_{\text {mean }}$ & 0.988 & $0.990-1.006$ & 0.610 \\
\hline
\end{tabular}

$\mathrm{D}_{\max }$ : maximum dose of intrathoracic stomach; $\mathrm{D}_{\text {mean }}$ : mean dose of intrathoracic stomach

with a $\mathrm{D}_{\max }$ more than $60 \mathrm{~Gy}$. The mean $\mathrm{V}_{60}$ for the group was $12.1 \%$, which was much higher than the QUANTEC standards. According to the study of Emami et al., 60 Gy of $1 / 3$ stomach was tolerant for TD5/5; therefore, we believed the risk of severe toxicities due to RT in our study would not be higher than the existing data. Meanwhile, we think it is still important to ensure that hotspots are minimized when using most conformal techniques.

Some of the previously summarized studies reported that RT toxicity was also related to irradiated volume and preformed dose-volume analysis for the stomach. Nakamura et al. [12] reported that $\mathrm{V}_{50}$ of the stomach $\geq 16 \mathrm{~cm}^{3}$ may be the best predictor for $\geq$ grade 2 acute gastrointestinal toxicity. Kim et al. showed a dosevolume analysis of GD toxicity in cirrhotic patients with $\mathrm{HCC}$ and suggested that $\mathrm{V}_{35} \geq 5 \%$ could predict $\geq$ grade 3 GD toxicity [22]. However, there is a lack of data on the evaluation of toxicity based on dose-volume analysis for the intrathoracic stomach using DVH parameters. In the current study, we confirmed the dose-volume effect for digestive toxicity. We found that $\mathrm{V}_{50}$ for the intrathoracic stomach was the most predictive factor for $\geq$ grade 2 gastric toxicity. Patients in the large-field group received a greater range of radiation exposure with the same prescribed dose, meaning that the volume of the intrathoracic stomach irradiated was higher than that in the small-field group. Thus, the large-field group had a higher risk of radiation toxicity than the small-field group, though statistical significance was not reached. In fact, literature on RT-induced stomach toxicity is relatively sparse, with insufficient data to arrive at firm dose-volume constraints for partial volume irradiation.

There were several limitations in our study. First, the volume of the stomach is variable; therefore, errors in our data were inevitable. However, patients were requested to avoid large meals or carbonated beverages before simulation and treatment to minimize variability in the volume and location of the stomach. Second, we record the toxicities mainly based on patients' symptoms rather than objective examinations. Third, selection bias may have influenced the results. If more patients were enrolled and observed for a longer time period, the values might change. Thus, a larger study is necessary to verify our results.

Therefore, it is acceptable to keep the maximum point dose to the intrathoracic stomach at more than $60 \mathrm{~Gy}$ or less for acute and late gastric toxicity for patients with esophageal cancer treated with radiotherapy after esophagectomy. A strong dose-volume relationship exists for the development of Grade 2 acute intrathoracic stomach toxicity in our study. Further studies are necessary to clarify the dose-volume relationship for intrathoracic stomach toxicity and to determine its dose constraint.

\section{CONFLICTS OF INTEREST}

All authors state that there are no conflicts of interest.

\section{REFERENCES}

1. van Hagen P, Hulshof MC, van Lanschot JJ, Steyerberg EW, van Berge Henegouwen MI, Wijnhoven BP, Richel DJ, Nieuwenhuijzen GA, Hospers GA, Bonenkamp JJ, Cuesta MA, Blaisse RJ, Busch OR, et al. Preoperative chemoradiotherapy for esophageal or junctional cancer. N Engl J Med. 2012; 366:2074-2084.

2. Kumagai K, Rouvelas I, Tsai JA, Mariosa D, Klevebro F, Lindblad M, Ye W, Lundell L, Nilsson M. Meta-analysis of postoperative morbidity and perioperative mortality in patients receiving neoadjuvantchemotherapy or 
chemoradiotherapy for resectable oesophageal and gastrooesophageal junctional cancers. $\mathrm{Br}$ J Surg. 2014; 101:321-338.

3. Nakagawa S, Kanda T, Kosugi S, Ohashi M, Suzuki T, Hatakeyama K. Recurrence pattern of squamous cell carcinoma of the thoracic esophagus after extended radical esophagectomy with three-field lymphadenectomy. J Am Coll Surg. 2004; 198:205-211.

4. Chen G, Wang Z, Liu XY, Liu FY. Recurrence pattern of squamous cell carcinoma in the middle thoracic esophagus after modified Ivor-Lewis esophagectomy. World J Surg. 2007; 31:1107-1114.

5. van Hagen $\mathrm{P}$, Wijnhoven BP, Nafteux P, Moons J, Haustermans K, De Hertogh G, van Lanschot JJ, Lerut T. Recurrence pattern in patients with a pathologically complete response after neoadjuvant chemoradiotherapy and surgery for oesophageal cancer. Br J Surg. 2013; 100:267-273.

6. Liu Q, Cai XW, Wu B, Zhu ZF, Chen HQ, Fu XL. Patterns of Failure after Radical Surgery among Patients with Thoracic Esophageal Squamous Cell Carcinoma: Implications for the Clinical Target Volume Design of Postoperative Radiotherapy. PLoS One. 2014; 9:e97225.

7. Cai WJ, Xin PL. Pattern of relapse in surgical treated patients with thoracic esophageal squamous cell carcinoma and its possible impact on target delineation for postoperative radiotherapy. Radiother Oncol. 2010; 96:104-107.

8. Chen J, Pan J, Zheng X, Zhu K, Li J, Chen M, Wang J, Liao Z. Number and location of positive nodes, postoperative radiotherapy, and survival after esophagectomy with three-field lymph node dissection for thoracic esophageal squamous cell carcinoma. Int J Radiat Oncol Biol Phys. 2012; 82:475-482.

9. Schreiber D, Rineer J, Vongtama D, Wortham A, Han P, Schwartz D, Choi K, Rotman M. Impact of postoperative radiation after esophagectomy for esophageal cancer. J Thorac Oncol. 2010; 5:244-250.

10. Kavanagh BD, Pan CC, Dawson LA, Das SK, Li XA, Ten Haken RK, Miften M. Radiation dose-volume effects in the stomach and small bowel. Int. J. Radiation Oncology Biol. Phys. 2010; 76:S101-S107.

11. Huang J, Robertson JM, Ye H, Margolis J, Nadeau L. Dosevolume analysis of predictors for gastrointestinal toxicity after concurrent full-dose gemcitabine and radiotherapy for locally advanced pancreatic adenocarcinoma. Int J Radiat Oncol Biol Phys. 2012; 83:1120-1125.

12. Nakamura A, Shibuya K, Matsuo $Y$, Nakamura M, Shiinoki T, Mizowaki T, Hiraoka M. Analysis of dosimetric parameters associated with acute gastrointestinal toxicity and upper gastrointestinal bleeding in locally advanced pancreatic cancer patients treated with gemcitabine-based concurrent chemoradiotherapy. Int J Radiat Oncol Biol Phys. 2012; 84:369-375.

13. Cheng SH, Lin YM, Chuang VP, Yang PS, Cheng JC, Huang AT, Sung JL. A pilot study of three-dimensional conformal radiotherapy in unresectable hepatocellular carcinoma. J Gastroenterol Hepatol. 1999; 14:1025-1033.

14. Li B, Yu J, Wang L, Li C, Zhou T, Zhai L, Xing L. Study of local three-dimensional conformal radiotherapy combined with transcatheter arterial chemoembolization for patients with stage III hepatocellular carcinoma. Am J Clin Oncol. 2003; 26:e92-e99.

15. Park HC, Seong J, Han KH, Chon CY, Moon YM, Suh CO. Dose-response relationship in local radiotherapy for hepatocellular carcinoma. Int J Radiat Oncol Biol Phys. 2002; 54:150-155.

16. Milano MT, Chmura SJ, Garofalo MC, Rash C, Roeske JC, Connell PP, Kwon OH, Jani AB, Heimann R. Intensitymodulated radiotherapy in treatment of pancreatic and bile duct malignancies: toxicity and clinical outcome. Int $\mathrm{J}$ Radiat Oncol Biol Phys. 2004; 59:445-453.

17. Qiao XY, Wang W, Zhou ZG, Gao XS, Chang JY. Comparison of efficacy of regional and extensive clinical target volumes in postoperative radiotherapy for esophageal squamous cell carcinoma. Int J Radiat Oncol Biol Phys. 2008; 70:396-402.

18. Cosset JM, Henry-Amar M, Burgers JM, Noordijk EM, Van der Werf-Messing B, Meerwaldt JH, van der Schueren E. Late radiation injuries of the gastrointestinal tract in the $\mathrm{H} 2$ and H5 EORTC Hodgkin's disease trials: Emphasis on the role of exploratory laparotomy and fractionation. Radiother Oncol. 1988; 13:61-68.

19. Adelstein DJ, Rice TW, Rybicki LA, Saxton JP, Videtic GM, Murthy SC, Mason DP, Rodriguez CP, Ives DI. Mature results from a phase II trial of postoperative concurrent chemoradiotherapy for poor prognosis cancer of the esophagus and gastroesophageal junction. J Thorac Oncol. 2009; 4:1264-1269.

20. Emami B, Lyman J, Brown A, Coia L, Goitein M, Munzenrider JE, Shank B, Solin LJ, Wesson M. Tolerance of normal tissue to therapeutic irradiation. Int J Radiat Oncol Biol Phys. 1991; 21:109-122.

21. Bockbrader M, Kim E. Role of intensity-modulatedradiation therapy in gastrointestinal cancer. ExpertRev Anticancer Ther. 2009; 9:637-647.

22. Kim H, Lim do H, Paik SW, Yoo BC, Koh KG, Lee JH, Choi MS, Park W, Park HC, Huh SJ, Choi DH, Ahn YC. Predictive factors of gastroduodenal toxicity in cirrhotic patients after three-dimensional conformal radiotherapy for hepatocellular carcinoma. Radiother Oncol. 2009; 93:302-306. 